\title{
Genetic controls of Th17 cell differentiation and plasticity
}

\author{
Chen Dong ${ }^{1}$ \\ Department of Immunology and Center for Inflammation and Cancer \\ MD Anderson Cancer Center \\ Houston, TX, USA \\ ${ }^{1}$ Correspondence: Tel, 1-713-563-3203; \\ Fax, 1-713-563-0604; E-mail, cdong@mdanderson.org \\ DOI 10.3858/emm.2011.43.1.007
}

Accepted 22 December 2010

Available Online 23 December 2010

Abbreviation: Th cells, T helper cells

\begin{abstract}
$\mathrm{CD4}^{+} \mathrm{T}$ lymphocytes play a major role in regulation of adaptive immunity. Upon activation, naïve T cells differentiate into different functional subsets. In addition to the classical Th1 and Th2 cells, several novel effector $T$ cell subsets have been recently identified, including Th17 cells. There has been rapid progress in characterizing the development and function of Th17 cells. Here I summarize and discuss on the genetic controls of their differentiation and emerging evidence on their plasticity. This information may benefit understanding and treating immune diseases.
\end{abstract}

Keywords: CD4-positive T-lymphocytes; cell differentiation; cytokines; Th17 cells; transcription factors

After activation by antigen-presenting cells (APC), naïve, antigen-specific $\mathrm{CD} 4^{+} \mathrm{T}$ cells differentiate into effector $T$ cells. Two decades ago, Coffman and Mosman first discovered the heterogeneity of effector T cells, which were then named as Th1 or Th2 cells (Mosmann and Coffman, 1989). Th1 and Th2 cells are differentially induced and regulate immunity against intracellular and extracellular pathogens, respectively, as well as immunopathologies such as autoimmunity and allergy. The Th1/Th2 dichotomy has dominated the field of immune regulation until five years ago when IL17-expressing $T$ cells were proposed to be a third lineage of helper T cells (Harrington et al., 2005; Park et al., 2005). In addition to these so-called Th17 cells, additional $T$ cell subsets were also discovered or studied, including $T$ follicular helper (Tfh) cells and IL-9-expressing "Th9" cells, etc.
Th cell differentiation is instructed by distinct environmental cytokines, which signals through STAT or other inducible but generally ubiquitous transcription factors. These factors then upregulate the expression of lineage-specific transcription factors, which function not only to promote its own lineage differentiation but also to inhibit the alternate differentiation pathways. There are extensive cross-regulations of lineage-determining transcription factors. Moreover, there is growing evidence that Th cell lineage commitment can be plastic in certain circumstances. Here, I summarize our current understanding on the genetic controls of Th17 cell lineage differentiation and discuss on the evidence and mechanisms underlying their plasticity.

\section{Transcriptional control of Th17 cell differentiation}

Th17 cell differentiation can be induced by the combination of TGF $\beta$ and IL-6 or IL-21 (Dong, 2008). IL-1 also plays a crucial role in early Th17 cell differentiation (Chung et al., 2009). Several transcription factors have been shown as critical regulators of Th17 cell differentiation.

\section{STAT3}

STAT3 has been reported to be a crucial component of IL-6-mediated Th17-cell regulation. T cells deficient in SOCS3 (a negative regulatory of STAT3) were first found to have enhanced STAT3 activity and IL-17 production in response to IL-23 (Chen et al., 2006). In the absence of STAT3 in T cells, defects were oberved not only in IL-17 production, but also in the expression of IL-17F, IL-22 and IL-23R (Yang et al., 2007). Subsequently, STAT3 was also reported to be important for IL-21 expression and for IL-21-mediated Th17cell differentiation (Nurieva et al., 2007; Zhou et al., 2007). Importantly, STAT3 deficiency greatly decreased the expression of ROR $\gamma \mathrm{t}$ and ROR $\alpha$, which are now known to be Th17-cell lineagespecific transcription factors (Yang et al., 2007; Yang et al., 2008b). These results indicate an essential function of STAT3 in the global regulation of Th17-cell gene expression programs, possibly through the induction of lineage-specific transcription factors. Consistently, in human hyper-IgE patients with STAT3 mutation, Th17 differentiation 
was found to be defective (Milner et al., 2008).

\section{Smads}

TGF $\beta$ together with IL-6 drive Th17 cell differentiation. However, how TGF $\beta$ signals in this process was not understood for some time. TGF $\beta$ signaling through a heteromeric TGF $\beta$ RII and TGF $\beta$ RI complex, activates the phosphorylation of Smad2 and Smad3, which associate with the common partner Smad4, and translocates to the nucleus (Feng and Derynck, 2005). Yang et al. showed that inhibition of TGF $\beta$ signaling in T cells suppressed Th17 cell differentiation (Yang et al., 2008a). However, Smad4 was not required for Th17 cell differentiation in this study. Furthermore, Martinez et al reported that in T cells deficient in Smad3, Th17 cell differentiation was enhanced in vitro and in vivo (Martinez et al., 2009). Subsequently, Smad2 was reported by several groups to positively regulate Th17 cell differentiation (Malhotra et al., 2010; Martinez et al., 2010; Takimoto et al., 2010). T cells deficient in Smad2 had substantial reduced Th17 differentiation in vitro. Also Malhotra et al. and Martinez et al. reported that Smad2 is required for Th17 response in vivo in host defense to pathogen infection and in autoimmune disease (Malhotra et al., 2010; Martinez et al., 2010). Takimoto et al. analyzed T cells deficient in both Smad2 and Smad3 and found that they even had a greater defect in Th17 cell differentiation than Smad2 ${ }^{-/-} \mathrm{T}$ cells (Takimoto et al., 2010). Smad3 likely plays a redundant role in the absence of Smad2.

How Smad2 regulates Th17 cell differentiation is not understood. In the absence of Smad2 or both Smad2 and 3, there was no defect in upregulation of Th17-specific transcription factors (Martinez et al., 2010; Takimoto et al., 2010). Martinez et al showed that Smad2 enhanced Th17 cell differentiation driven by ROR $\gamma \mathrm{t}$ (Martinez et al., 2010). It is thus possible that Smad2 is not required for early Th17 cell differentiation but may serve as a co-factor for ROR $\gamma$ t to mediate the expression of Th17-specific genes. The direct targets of Smad2 need to be determined by genome-wide approaches.

\section{ROR $\gamma \mathrm{t} / \mathrm{ROR} \alpha$}

Th-cell lineage commitment is mediated by lineage-specific transcription factors. Similar to T-bet in Th1 cells and GATA3 in Th2 cells, two retinoic acid-related orphan receptor were recently discovered to regulate Th17-cell differentiation. ROR $\gamma$, encoded by the Rorc gene, and ROR $\alpha$ both belong to the retinoic acid-related orphan nuclear hormone receptor family that also includes $\mathrm{ROR} \beta$ (Jetten, 2004). An isoform of ROR $\gamma, R O R \gamma t$ is exclusively expressed in cells of the immune system (Eberl and Littman, 2003). Recently, Ivanov et al. identified ROR $\gamma \mathrm{t}$ as a candidate master regulator that drives Th17-cell lineage differentiation (Ivanov et al., 2006). ROR $\gamma$ t expression is induced by TGF $\beta$ or IL-6, and overexpression of ROR $\gamma$ t promoted Th17-cell differentiation when both Th1- and Th2-cell differentiation were blocked. Conversely, ROR $\gamma$ t-deficient T cells were defective in Th17-cell differentiation, especially in terms of IL-17 and IL-17F expression, in response to TGF $\beta$ and IL-6 or IL-21 (Ivanov et al., 2006; Nurieva et al., 2007; Zhou et al., 2007).

In spite of these findings, residual Th17 cells are still present in the absence of ROR $\gamma \mathrm{t}$ and mice lacking T-cell expression of ROR $y$ t can still develop EAE disease, which indicates that other factors are also involved. Recently, Yang et al. reported that $\mathrm{ROR} \alpha$ is also expressed by Th17 cells; ROR $\alpha$ expression was induced by TGF $\beta$ and IL- 6 in a STAT3-dependent manner (Yang et al., 2008b). Similar to ROR $\gamma \mathrm{t}$, ROR $\alpha$ overexpression promoted Th17-cell differentiation when Th1- and Th2-cell differentiation was inhibited, which could occur independent of ROR $\gamma$. However, ROR $\alpha$ deficiency in $T$ cells only resulted in a selective decrease in IL-17 and IL-23R expression and had a very moderate inhibitory effect on EAE (Yang et al., 2008b). Yang et al. further showed that overexpression of ROR $\alpha$ and ROR $\gamma$ t had a synergistic effect in promoting Th17-cell differentiation, especially when $T$ cells were cultured under polarized differentiation conditions for Th1 cells or Treg cells (Yang et al., 2008b). In addition, compound mutations in both factors completely inhibited Th17cell differentiation in vitro and in vivo and entirely suppressed the development of EAE (Yang et al., 2008b). Thus, ROR $\alpha$ and ROR $\gamma$ t have similar and redundant functions.

\section{IRF4}

In addition to the ROR factors, interferon-regulatory factor 4 (IRF4) was recently shown to be essential for Th17-cell differentiation (Brustle et al., 2007). IRF4 deficiency completely inhibited Th17cell differentiation and protected mice against EAE. ROR $\gamma \mathrm{t}$ expression was markedly decreased in Irf $4^{-1-} \mathrm{T}$ cells following treatment with TGF $\beta$ and IL-6, which suggests that IRF4 might be upstream of ROR $\gamma$ t (Brustle et al., 2007). However, ROR $\gamma \mathrm{t}$ overexpression in Irf4 ${ }^{-1-} \mathrm{T}$ cells only partially restored Th17-cell differentiation. Therefore, the pre- 
cise function of IRF4 remains to be determined.

\begin{abstract}
Ahr
The aryl hydrocarbon receptor (AHR) is a type I nuclear receptor that has been recently reported by two groups that AHR plays a crucial role in Th17 differentiation. Both regulatory $\mathrm{T}$ cells and Th17 cells express AHR (Quintana et al., 2008; Veldhoen et al., 2008), although the expression of this receptor is significantly higher in Th17 cells compared to Tregs or any other Th subset (Veldhoen et al., 2008). Interestingly, both Treg and Th17 differentiation is not impaired in AHR-deficient mice. However, Th17 cells from AHR-deficient mice do not express IL-22 (Veldhoen et al., 2008). Activation of AHR with 6-formylindolo [3,2-b]carbazole (FICZ) during Th17 differentiation significantly enhances IL-17, IL-17F and most strikingly IL-22 levels in vitro (Quintana et al., 2008; Veldhoen et al., 2008). Furthermore, in vivo administration of FICZ during MOG immunization leads to increased Th17-specific genes expression and more severe EAE induction (Quintana et al., 2008; Veldhoen et al., 2008).
\end{abstract}

\section{Batf}

Batf is a member of AP-1 transcription factor family. Batf mRNA expression is significantly upregulated in activated $\mathrm{T}$ cells but not unique to Th17 cells. Recently, Schraml et al. generated Batf-deficient mice and showed that the differentiation of Th17 cells was completely impaired. Moreover, these mice also failed to produce IL-17 in both $\mathrm{CD} 4^{+}$and $\mathrm{CD} 8^{+} \mathrm{T}$ cells in vivo (Schraml et al., 2009). Consistent with this finding, Batf-deficient mice were resistant to experimental autoimmune encephalomyelitis (EAE). Batf-deficient cells were capable of inducing both $R O R \alpha$ and ROR $\gamma t$ at an early time point. However, these cells were incapable of maintaining their expression. Moreover, overexpression of the orphan nuclear receptor ROR $\mathrm{tt}$ in Batf $^{\prime-}$ cells failed to restore Th17 cell generation. Schraml et al. analyzed Batf binding to various Th17-associated genes and found that Batf forms a heterodimer with JunB in Th17 cells, and binds to IL-17, IL-21 and IL-22 promoters as well as two intergenic regions between the IL-17A and the IL-17F genes (Schraml et al., 2009).

\section{Ikb $\zeta$}

$I \kappa B \zeta$ (encoded by the Nfkbiz gene), a nuclear $I_{\kappa} B$ family member, has recently been shown to be required for Th17 cell development (Okamoto et al., 2010). The overexpression of $I \kappa B \zeta$ is not sufficient in driving Th17 cell differentiation but synergizes with $\mathrm{ROR} \gamma \mathrm{t}$ or $\mathrm{ROR} \alpha$. I $\mathrm{kB} \zeta$ may act by binding directly to the regulatory region of the IL-17 gene. In vivo, Nfkbiz ${ }^{-1-}$ mice have a defect in Th17 development and are resistant to EAE.

\section{Epigenetic control of IL-17/IL-17F expression}

Lineage-specific transcription factors can function by binding cis elements in the cytokine gene loci to initiate or maintain a selective and heritable epigenetic configuration. Akimzhanov et al. first reported that the promoters of II17 and II17F genes in Th17 cells, but not in Th1 or Th2 cells, had histone modifications that are typically associated with active, transcribing loci, - that is acetylated histone $\mathrm{H} 3$ and histone $\mathrm{H} 4$ trimethylated at lysine 4 residues (Akimzhanov et al., 2007). Moreover, 8 conserved, non-coding sequences (CNS) in the I/17-I/17f gene locus, which are also associated with acetylated histone $\mathrm{H} 3$ in Th17 cells, were identified, raising the possibility that these elements may regulate the coordinated expression of IL-17 and IL-17F in Th17 cells. One of these elements, CNS2, has studied in greater details. Histone $\mathrm{H} 3$ acetylation at CNS2 is induced by TGF $\beta$ and IL- 6 and both ROR $\alpha$ and ROR $\gamma$ t can bind to the ROR response elements (RORE) sites in this region (Yang et al., 2008b). Interestingly, although the expression of ROR $\alpha$ or ROR $\gamma \mathrm{t}$ in EL4 cells could not activate the transcription of a luciferase reporter downstream of a minimal /117 gene promoter, coupling the expression with CNS2 in the reporter construct confers ROR inducibility, arguing that the ROREs in CNS2 are functional. More recently, RUNX1 factor was found to cooperate with ROR $\gamma$ in activating this element (Zhang et al., 2008). Whether CNS2 is required for ROR $\gamma$ t-mediated transcription of the IL-17 gene remains to be determined genetically.

\section{Reciprocal determination of Th17 and Treg differentiation}

Differentiation of Th17 and regulatory T cells, both of which depend on TGF- $\beta$, shares a reciprocal regulation. It is not clear whether different pathways or components downstream of TGF $\beta$ signaling is involved in Th17 and TGF $\beta$-induced Treg (iTreg) generation; Smad2, 3 and 4 was recently 
reported each to be partially required for iTreg generation while it was dispensable for generation of Th17 cells (Yang et al., 2008a; Martinez et al., 2009, 2010; Malhotra et al., 2010; Takimoto et al., 2010).

Increasing concentrations of TGF- $\beta$ can augment Foxp3 levels and reduce IL-23R expression, even in the presence of low concentrations of IL-6, shifting the differentiation of TH cells from Th17 towards regulatory T cells (Zhou et al., 2008). Recently, it was demonstrated that once the expression of Foxp3 increases, it can directly interact with ROR $\gamma$ t, leading to inhibition of its transcriptional activity (Zhou et al., 2008). Indeed, cells co-expressing Foxp3 and ROR $\gamma$ t in lamina propria had lower IL-17 production compared to cells expressing ROR $\gamma$ t alone (Zhou et al., 2008). Meanwhile, Foxp3 LxxLL sequence in exon 2 was shown to associate with the newly identified Th17-specific transcription factor ROR $\gamma$ (Du et al., 2008), suggesting a potential role of Foxp3 in suppression of Th17 development through inhibition of both ROR $\alpha$ and ROR $\gamma$ t. Indeed, Foxp3 overexpression under Th17 polarizing conditions inhibited IL-17, IL-17F, IL-21 and IL-22 cytokine expression but did not affect ROR $\alpha$ or ROR $\gamma$ mRNA levels. Furthermore, it was found that not only the LxxLL sequence, but also the TIP60/ HDAC7 domain of Foxp3 is required for its inhibitory effect on ROR $\gamma \mathrm{t}$ and $\mathrm{ROR} \alpha$, suggesting that Foxp3 interacts with RORs and recruits histone deacetylases to Th17-specific genes, thus inhibiting the transcription of those genes (Yang et al., 2008a).

Induction of TGF $\beta$-induced Foxp3 $^{+}$cells is facilitated by IL-2. Mechanistically, IL-2 activates STAT5, which suppresses IL-17 expression by directly binding to the IL-17 gene promoter (Laurence et al., 2007). Recently, the transcription factor Ets-1 was shown to inhibit Th17-cell differentiation (Moisan et al., 2007). Ets $1^{-1-} \mathrm{T}$ cells exhibited greatly increased Th17-cell differentiation in response to TGF $\beta$ and IL-6, as characterized by increased IL-17, IL-17F, IL-22 and IL-23R expression (Moisan et al., 2007). Ets-1 is required for IL-2-mediated inhibition of Th17-cell development (Moisan et al., 2007).

Although Foxp3 has a strong inhibitory role in Th17 differentiation, IL-6 has been found to downregulate Foxp3 expression in TGF $\beta$-induced and thymically derived Treg cells and together with IL-1, to upregulate Th17-specific gene expression (Xu et al., 2007; Yang et al., 2008a). STAT3 was required for both Foxp3 downregulation as well as IL-17 expression while RORs were only for the latter. These results suggest plasticity of Treg/Th17 differentiation programs.

\section{Th17 cell plasticity}

In immune responses against infection and autoimmune disease models, Th1 and Th17 cells often develop simultaneously. Perturbation of one pathway may result in augmentation of the other. In T-bet-deficient mice in comparison to wild-type counterparts, elevated IL-17 expression levels and increased numbers of IL-17-producing cells were observed upon MOG/CFA immunization (Park et al., 2005). T-bet was recently described to directly inhibit RORyt expression (Lazarevic et al., 2010). In a mouse model for human autoimmune myocarditis, mice lacking T-bet developed more severe disease compared to $\mathrm{T}^{- \text {bet }^{+/+}}$control mice (Rangachari et al., 2006). Moreover, the $\mathrm{T}^{- \text {bet }^{-{ }^{-}}}$mice demonstrated a marked increase in production of the IL-23-dependent cytokine IL-17 by heartinfiltrating lymphocytes (Rangachari et al., 2006). Thus, these results suggest that T-bet might serve as a negative regulator for Th17 cell differentiation, the mechanism of which remains to be determined.

On the other hand, in vitro generated Th17 cells are not stable in maintaining their cytokine expression capacities in vitro and can be converted into Th1 cells in lymphopenic environments (Lee et al., 2009; Martin-Orozco et al., 2009a). However, these cells maintained their phenotypes in normal mice or tumor-bearing mice (Martin-Orozco et al., 2009b; Nurieva et al., 2009). These results suggest that newly generated Th17 cells are not stable intrinsically and may require environmental "help" to maintain their program.

The basis for the plasticity of Th17 cells and molecular controls of their maintenance or reprogramming are still not very well understood. Wei et al. recently conducted genome-wide histone H3 lysine 4 (H3K4) and lysine 27 (H3K27) association study on naive, Th1, Th2, Th17, iTreg, and natural Treg (nTreg) cells (Wei et al., 2009). In Th17 cells, they found that epigenetic modifications of the Il17 gene well correlate with their transcriptional status. However, the genes encoding transcription factors like Tbx21 exhibit "binary" modifications of chromatins, i.e. with both activating and repressive marks. It was postulated that this phenomenon may underlie the plasticity of Th17 cells. Indeed, T-bet can be elevated in Th17 cells in the presence of IL-12 (Lee et al., 2009; Nurieva et al., 2009). Mukasa et al. even showed that under the influence of T-bet and STAT4, Th17 cells quickly lose the lineage-specific epigenetic configuration (Mukasa et al., 2010), suggesting a more active and direct role of these factors in 
re-programming of Th17 cells.

\section{Conclusion and future perspectives}

Since discovery, Th17 cells have emerged as an important mediator of human immune diseases, which is supported by recent clinical trials using anti-IL-17 (Hueber et al., 2010). There has been very rapid understanding on the transcriptional regulation of Th17 cell differentiation and a number of trans-acting factors have been identified to be important in this process. How these factors work individually and together still require further elucidation. Another important emerging issue is the plasticity of Th17 cells. Although re-differentiation of Th17 cells has been observed in several circumstances, the physiological relevance and significance are still unclear. Also what factors regulate the maintenance and plasticity of Th17 cells would need to be determined. Nonetheless, our current understanding on Th17 cells and future development in the field will assist more effective and rational treatment of human diseases.

\section{References}

Akimzhanov AM, Yang XO, Dong C. Chromatin remodeling of interleukin-17 (IL-17)-IL-17F cytokine gene locus during inflammatory helper $\mathrm{T}$ cell differentiation. J Biol Chem 2007;282:5969-72

Brustle A, Heink S, Huber M, Rosenplanter C, Stadelmann C, Yu P, Arpaia E, Mak TW, Kamradt T, Lohoff M. The development of inflammatory $\mathrm{TH}-17$ cells requires interferon-regulatory factor 4. Nat Immunol 2007;8:958-66

Chen Z, Laurence A, Kanno Y, Pacher-Zavisin M, Zhu BM, Tato C, Yoshimura A, Hennighausen L, O'Shea JJ. Selective regulatory function of Socs3 in the formation of IL-17secreting T cells. Proc Natl Acad Sci USA 2006;103:8137-42

Chung Y, Chang SH, Martinez GJ, Yang XO, Nurieva R, Kang HS, Ma L, Watowich SS, Jetten AM, Tian Q, Dong C. Critical regulation of early Th17 cell differentiation by interleukin-1 signaling. Immunity 2009;30:576-87

Dong C. TH17 cells in development: an updated view of their molecular identity and genetic programming. Nat Rev Immunol 2008;8:337-48

Du J, Huang C, Zhou B, Ziegler SF. Isoform-specific inhibition of ROR $\alpha$-mediated transcriptional activation by human FOXP3. J Immunol 2008;180:4785-92

Eberl G, Littman DR. The role of the nuclear hormone receptor ROR $\gamma$ t in the development of lymph nodes and Peyer's patches. Immunol Rev 2003;195:81-90

Feng XH , Derynck R. Specificity and versatility in TGF- $\beta$ signaling through Smads. Annu Rev Cell Dev Biol 2005;

\section{1:659-93}

Harrington LE, Hatton RD, Mangan PR, Turner H, Murphy TL, Murphy KM, Weaver CT. Interleukin 17-producing CD4+ effector T cells develop via a lineage distinct from the Thelper type 1 and 2 lineages. Nat Immunol 2005;6:1123-32

Hueber W, Patel DD, Dryja T, Wright AM, Koroleva I, Bruin G, Antoni C, Draelos Z, Gold MH, Group tPS, Durez P, Tak PP, Gomez-Reino JJ, Group tRAS, Foster CS, Kim RY, Samson CM, Falk NS, Chu DS, Callanan D, Nguyen QD, Group tUS, Rose K, Haider A, Di Padova F. Effects of AIN457, a Fully Human Antibody to Interleukin-17A, on Psoriasis, Rheumatoid Arthritis, and Uveitis. Sci Transl Med 2010; 2:52ra72

Ivanov, II, McKenzie BS, Zhou L, Tadokoro CE, Lepelley A, Lafaille JJ, Cua DJ, Littman DR. The orphan nuclear receptor RORgammat directs the differentiation program of proinflammatory IL-17+ T helper cells. Cell 2006;126:1121-33

Jetten AM. Recent advances in the mechanisms of action and physiological functions of the retinoid-related orphan receptors (RORs). Curr Drug Targets Inflamm Allergy 2004; 3:395-412

Laurence A, Tato CM, Davidson TS, Kanno Y, Chen Z, Yao Z, Blank RB, Meylan F, Siegel R, Hennighausen L, Shevach EM, O'Shea JJ. Interleukin-2 Signaling via STAT5 Constrains T Helper 17 Cell Generation. Immunity 2007;26: 371-81

Lazarevic V, Chen X, Shim JH, Hwang ES, Jang E, Bolm AN, Oukka M, Kuchroo VK, Glimcher LH. T-bet represses TH17 differentiation by preventing Runx1-mediated activation of the gene encoding ROR $\gamma \mathrm{t}$. Nat Immunol 2010;12:96-104

Lee YK, Turner H, Maynard CL, Oliver JR, Chen D, Elson CO, Weaver CT. Late developmental plasticity in the Thelper 17 lineage. Immunity 2009;30:92-107

Malhotra N, Robertson E, Kang J. SMAD2 is essential for TGF $\beta$-mediated Th17 cell generation. J Biol Chem 2010; 285:29044-8

Martinez GJ, Zhang Z, Chung Y, Reynolds JM, Lin X, Jetten $A M$, Feng $X H$, Dong $C$. Smad3 differentially regulates the induction of regulatory and inflammatory $\mathrm{T}$ cell differentiation. J Biol Chem 2009;284:35283-6

Martinez GJ, Zhang Z, Reynolds JM, Tanaka S, Chung Y, Liu T, Robertson E, Lin X, Feng XH, Dong C. Smad2 positively regulates the generation of Th17 cells. J Biol Chem 2010;285:29039-43

Martin-Orozco N, Chung Y, Chang SH, Wang YH, Dong C. Th17 cells promote pancreatic inflammation but only induce diabetes efficiently in lymphopenic hosts after conversion into Th1 cells. Eur J Immunol 2009a;39:216-24

Martin-Orozco N, Muranski P, Chung Y, Yang XO, Yamazaki T, Lu S, Hwu P, Restifo NP, Overwijk WW, Dong C. Thelper 17 cells promote cytotoxic T cell activation in tumor immunity. Immunity 2009b;31:787-98

Milner JD, Brenchley JM, Laurence A, Freeman AF, Hill BJ, Elias KM, Kanno Y, Spalding C, Elloumi HZ, Paulson ML, Davis J, Hsu A, Asher AI, O/'Shea J, Holland SM, Paul WE, Douek DC. Impaired TH17 cell differentiation in subjects with 
autosomal dominant hyper-lgE syndrome. Nature 2008; 452:773-6

Moisan J, Grenningloh R, Bettelli E, Oukka M, Ho IC. Ets-1 is a negative regulator of Th17 differentiation. J Exp Med 2007;204:2825-35

Mosmann TR, Coffman RL. TH1 and TH2 cells: different patterns of lymphokine secretion lead to different functional properties. Annu Rev Immunol 1989;7:145-73

Mukasa R, Balasubramani A, Lee YK, Whitley SK, Weaver BT, Shibata Y, Crawford GE, Hatton RD, Weaver CT. Epigenetic instability of cytokine and transcription factor gene loci underlies plasticity of the Thelper 17 cell lineage. Immunity 2010;32:616-27

Nurieva R, Yang XO, Martinez G, Zhang Y, Panopoulos AD, Ma L, Schluns K, Tian Q, Watowich SS, Jetten AM, Dong C. Essential autocrine regulation by IL-21 in the generation of inflammatory T cells. Nature 2007;448:480-3

Nurieva R, Yang XO, Chung Y, Dong C. Cutting edge: in vitro generated Th17 cells maintain their cytokine expression program in normal but not lymphopenic hosts. J Immunol 2009;182:2565-8

Okamoto K, Iwai Y, Oh-hora M, Yamamoto M, Morio T, Aoki $\mathrm{K}$, Ohya K, Jetten AM, Akira S, Muta T, Takayanagi H. IкB regulates $\mathrm{TH} 17$ development by cooperating with ROR nuclear receptors. Nature 2010;464:1381-5

Park H, Li Z, Yang XO, Chang SH, Nurieva R, Wang YH, Wang Y, Hood L, Zhu Z, Tian Q, Dong C. A distinct lineage of CD4 $T$ cells regulates tissue inflammation by producing interleukin 17. Nat Immunol 2005;6:1133-41

Quintana FJ, Basso AS, Iglesias AH, Korn T, Farez MF, Bettelli E, Caccamo M, Oukka M, Weiner HL. Control of Treg and TH17 cell differentiation by the aryl hydrocarbon receptor. Nature 2008;453:65-71

Rangachari M, Mauermann N, Marty RR, Dirnhofer S, Kurrer MO, Komnenovic V, Penninger JM, Eriksson U. T-bet negatively regulates autoimmune myocarditis by suppressing local production of interleukin 17. J Exp Med 2006;203:2009-19

Schraml BU, Hildner K, Ise W, Lee W-L, Smith WAE, Solomon B, Sahota G, Sim J, Mukasa R, Cemerski S, Hatton $\mathrm{RD}$, Stormo GD, Weaver CT, Russell JH, Murphy TL, Murphy $\mathrm{KM}$. The AP-1 transcription factor Batf controls TH17 differentiation. Nature 2009;460:405-9

Takimoto T, Wakabayashi Y, Sekiya T, Inoue N, Morita R, Ichiyama K, Takahashi R, Asakawa M, Muto G, Mori T,
Hasegawa E, Shizuya S, Hara T, Nomura M, Yoshimura A. Smad2 and Smad3 are redundantly essential for the TGF- $\beta$-mediated regulation of regulatory T plasticity and Th1 development. J Immunol 2010;185:842-55

Veldhoen M, Hirota K, Westendorf AM, Buer J, Dumoutier L, Renauld JC, Stockinger B. The aryl hydrocarbon receptor links TH17-cell-mediated autoimmunity to environmental toxins. Nature 2008;453:106-9

Wei G, Wei L, Zhu J, Zang C, Hu-Li J, Yao Z, Cui K, Kanno Y, Roh T-Y, Watford WT, Schones DE, Peng W, Sun H-w, Paul WE, O'Shea JJ, Zhao K. Global mapping of H3K4me3 and H3K27me3 reveals specificity and plasticity in lineage fate determination of differentiating CD4+ T cells. Immunity 2009;30:155-67

Xu L, Kitani A, Fuss I, Strober W. Cutting edge: regulatory T cells induce CD4+CD25-Foxp3- T cells or are self-induced to become Th17 cells in the absence of exogenous TGF- $\beta$. J Immunol 2007;178:6725-9

Yang XO, Panopoulos AD, Nurieva R, Chang SH, Wang D, Watowich SS, Dong C. STAT3 regulates cytokine-mediated generation of inflammatory helper T cells. J Biol Chem 2007;282:9358-63

Yang XO, Nurieva R, Martinez GJ, Kang HS, Chung Y, Pappu BP, Shah B, Chang SH, Schluns KS, Watowich SS, Feng XH, Jetten AM, Dong C. Molecular antagonism and plasticity of regulatory and inflammatory $\mathrm{T}$ cell programs. Immunity 2008a;29:44-56

Yang XO, Pappu BP, Nurieva R, Akimzhanov A, Kang HS, Chung Y, Ma L, Shah B, Panopoulos AD, Schluns KS, Watowich SS, Tian Q, Jetten AM, Dong C. T helper 17 lineage differentiation is programmed by orphan nuclear receptors ROR $\alpha$ and ROR $\gamma$. Immunity 2008b;28:29-39

Zhang F, Meng G, Strober W. Interactions among the transcription factors Runx1, ROR $\gamma$ t and Foxp3 regulate the differentiation of interleukin 17-producing T cells. Nat Immunol 2008;9:1297-306

Zhou L, Ivanov, II, Spolski R, Min R, Shenderov K, Egawa T, Levy DE, Leonard WJ, Littman DR. IL-6 programs TH-17 cell differentiation by promoting sequential engagement of the IL-21 and IL-23 pathways. Nat Immunol 2007;8:967-74

Zhou L, Lopes JE, Chong MM, Ivanov, II, Min R, Victora GD, Shen Y, Du J, Rubtsov YP, Rudensky AY, Ziegler SF, Littman DR. TGF- $\beta$-induced Foxp3 inhibits TH17 cell differentiation by antagonizing ROR $\gamma$ t function. Nature 2008;453:236-40 